\title{
DE LA OPACIDAD CIUDADANA AL ESPACIO PÚBLICO COMO CREACIÓN COLECTIVA: RECORRIENDO LA CALLE RECREATIVA EN LA CIUDAD DE ROSARIO (2010-2015).
}

\author{
FROM THE CITIZEN OPACITY TO THE PUBLIC SPACE AS A COLLECTIVE CREATION: \\ WALKING AROUND THE RECREATIONAL STREET IN THE CITY OF ROSARIO (2010- \\ 2015)
}

\section{Gisela Signorelli ${ }^{1}$}

\section{Resumen}

Las ciudades cada vez tienen más dificultades para cumplir con su función de ser un lugar de integración y cohesión social. (Ziccardi, 2008; Lindón, 2006; Mongin, 2006; Soldano, 2008; Janoschka, 2004; Di Virgilio y Rodríguez, 2015). La problemática de la fragmentación urbana avanza desde diferentes frentes como una sombra que opaca nuestras ciudades latinoamericanas. En ese marco el espacio público aparece como un núcleo central para el encuentro y la convivencia de sectores sociales que ya no se reconocen como ciudadanos de un mismo colectivo otorgándole una batalla ganada al miedo y los estigmas sociales.

El proyecto de Calle Recreativa en la ciudad de Rosario es un espacio que congrega cada domingo a públicos diversos a lo largo de $28 \mathrm{~km}$ de calles libres de circulación de cualquier vehículo a motor. Hay allí una apropiación diferente del espacio al de la cotidianeidad rosarina. ¿Quiénes se encuentran ahí? ¿En cuánto contribuye a la integración y la convivencia? ¿No se reproducen acaso las mismas fragmentaciones urbanas que también son parte de esa cotidianeidad de la ciudad? ¿Cómo se percibe allí al otro y al miedo a la alteridad? ¿Qué desafíos enfrenta?

Palabras claves: Espacio público, fragmentaciones urbanas, miedo, convivencia y participación, Calle Recreativa, Rosario

\begin{abstract}
Nowadays cities have more and more difficulties to lead their function of being a place for integration and social encounter. (Ziccardi, 2008; Lindón, 2006; Mongin, 2006; Soldano, 2008; Janoschka, 2004; Di Virgilio y Rodríguez, 2015). The problem of urban fragmentation draws on from different/varied positions as a shadow that darkens our Latin American cities. In this framework the public space appears as a central nucleus for the encounter and coexistence of social sectors due to the fact that they do not recognize themselves as citizens of a same group. Therefore, they grant a won battle to the fear and social stigma.

The Calle Recreativa Project in Rosario city is a space that gathers each Sunday diverse crowds along $28 \mathrm{~km}$ of streets free of any motor vehicle circulation. There is a different appropriation of the space to the daily nature in Rosario. Who gather there? How much does it contribute to the integration and communal living? Doesn't there happen the same urban fragmentations that are also part of the city daily nature? How is the other and the fear of otherness perceived? What challenges are faced?
\end{abstract}

Keywords: Public space, urban fragmentations, fear, daily nature and participation, Calle Recreativa, Rosario.

\footnotetext{
${ }^{1}$ Doctora en Ciencia Política. Docente Facultad de Ciencia Política y RR.II. UNR - Becaria Posdoctoral CONICET. E-mail: giselav_signorelli@yahoo.com.ar
} 


\section{INTRODUCCIÓN}

Rosario ha sido declarada por el BID como la ciudad más verde del país por su cantidad de espacio público por número de habitantes: 11,68 m2. Según datos oficiales el espacio verde urbano, se distribuye en 24 parques, 124 plazas, 51 plazoletas, 24 paseos y otros 228 espacios verdes, Ilegando su superficie total a 11,265 $\mathrm{km} 2$ que equivalen al 6,3\% de la superficie total de la ciudad. A su vez, Rosario es la primera en implementar en Argentina el proyecto de Ciclovías Recreativas de las Américas, conocida como Calle Recreativa: un espacio que congrega cada domingo a públicos diversos a lo largo de $28 \mathrm{~km}$ de calles libres de circulación de cualquier vehículo a motor.

Según la ordenanza de su creación (Nro. 8903) entre sus beneficios se mencionan: la recreación gratuita y el aprovechamiento del tiempo libre; la recuperación de las calles para el encuentro ciudadano, promoviendo la convivencia con valores democráticos; la adquisición de hábitos saludables; la promoción de la actividad física y el uso de medios alternativos de transporte que disminuye la contaminación ambiental y los niveles de ruidos.

¿Hay en la Calle Recreativa un "estar ahí" diferente del "pasar" por el espacio de la cotidianeidad rosarina? ¿Quiénes se encuentran allí? ¿En cuánto contribuye a la integración y la convivencia? ¿No se reproducen acaso las mismas fragmentaciones urbanas que son parte de esa cotidianeidad de la ciudad? ¿Cómo se percibe allí al otro y al miedo a la alteridad?

Este artículo tiene por objeto estudiar la constitución del espacio público como construcción colectiva capaz (o no) de romper con los estigmas sociales y el miedo al otro, suturando algunas de las fragmentaciones socio-territoriales que dividen a las ciudades latinoamericanas por nuestro días, acarreando problemas de convivencia y violencia urbana. Para ello realizaremos una aproximación descriptiva/analítica del Programa Calle Recreativa en Rosario durante su primer lustro de funcionamiento (2010-2015).

Desde su emergencia en los inicios de la Edad Moderna, la ciudad ha sido un espacio de aglutinación y de segregación, de centro y periferias, de incluidos y excluidos. Esa ciudad del siglo XVII y XVIII llega hasta nuestros días pero en su etapa actual la sociedad de la producción se ha convertido en la sociedad del consumo. Y así como en la sociedad moderna no todos podían ser los dueños de los medios de producción, en la sociedad posmoderna, no todos pueden ser consumidores. 
El consumo se presenta como un disciplinador social que establece los términos de la igualdad y la desigualdad entre los hombres y parece convertirse en un atributo de ciudadanía. Pues hemos pasado de vivir en ciudades definidas por sus límites físicos a otras donde lo urbano define una condición ciudadana con independencia de su referencia material (Silva, 2006). En ese contexto, las ciudades cada vez tienen más dificultades para cumplir con su función de ser un lugar de integración y cohesión social (Ziccardi, 2008; Lindón, 2006; Mongin, 2006; Soldano, 2008; Janoschka, 2004; Di Virgilio y Rodríguez, 2015; Carrión, 2007). La problemática de la fragmentación urbana avanza desde diferentes frentes como una sombra que opaca nuestras ciudades latinoamericanas. Existe un visible miedo al otro y por tanto, un repliegue en el espacio privado que parece ser un lugar de resguardo entre supuestos iguales: en definitiva, el miedo en la ciudad configura cierto tipo específico de ciudadanía, por momentos paradójica, en tanto supondría su negación (Segura, 2009:62).

En ese marco el espacio público puede ser un núcleo central para el encuentro y la convivencia de sectores sociales que ya no se reconocen como ciudadanos de un mismo colectivo social. Sin embargo, ese espacio se convierte en territorio en la medida que el ciudadano lo nombra, inscribe y lo vivencia; y en nuestros días para muchas personas la ciudad sólo pasa o es una válvula de escape, pero no se constituye en un lugar de arraigo dado que hay gente que padece la ciudad. Si les resulta ajena, si se la siente hostil, muchas veces la consecuencia es la violencia o simplemente la indiferencia. El no pertenecer te convierte en un paria urbano (Wanquant, 2013), en un fragmento marginal de una ciudad a la que no se puede acceder, a un no lugar (Augé, 2000). Sumado a ello, suelen pesar sobre estos sectores fuertes estigmas sociales en un sentido claramente desacreditador y de opacidad de sus atributos ciudadanos, que los llevan a sostener las mismas creencias que "los otros" sobre su identidad.

De este modo, el espacio público puede ser apenas una ilusión óptica de convivencia de lo diverso, en el cual las desigualdades se muestran superadas cuando en realidad, no son más que espacios vacíos que se limita a funciones circulatorias: un espacio del "pasar" y no del "estar ahi" (Lindón, 2006:29). O bien, ese espacio puede constituirse en un espacio estructurante (Carrión, 2016) de la vida urbana con potencialidades para contener las dinámicas excluyentes de la ciudad.

Como sostiene Borja (2013), el espacio público es el reflejo de la democracia en su dimensión territorial y ese espacio hoy está en crisis poniendo en cuestión la posibilidad de ejercer el derecho a la ciudad para un gran número de sus habitantes. 
La ciudad de Rosario no escapa a las relatadas dinámicas de disolución de la trama urbana. Desde hace unos años es la ciudad más violenta de Argentina con índices de homicidio que recién este año (2016) parecen amecetarse. A su vez, de acuerdo a datos proporcionados por el Servicio Público de la Vivienda, existen en Rosario 91 asentamientos precarios con 22.685 familias que totalizan 113.382 habitantes; lo que representa algo menos del 12 por ciento de la población total y ocupan un 10 por ciento de la superficie urbanizada (MR, 2004). Por su parte, el informe de la ONG Techo con datos actualizados al 2013, contabiliza 172 asentamientos irregulares en el Gran Rosario (50.550 familias), lo que equivale al 10\% de la población.

En los hechos, dicha pobreza estructural impacta produciendo la existencia de, por lo menos, dos ciudades: una con claras dificultades en el acceso a los derechos urbanos mínimos y otra dotada de los mismos y del valor simbólico de la centralidad urbana. Se produce una doble cartografía de la ciudad que se refleja en diferentes modos de habitarla y de gestionarla. Como contrapunto durante la década 2003-2013, la ciudad se consolidó como la principal plaza de crecimiento inmobiliario del país (con hasta 400 permisos de construcción por mes) con emprendimientos de gran escala sobre todo en la costa del Río Paraná y barrios abiertos en localidades pertenecientes al Gran Rosario, en lo que se llama un proceso de densificación vertical intensivo (Baremboim, 2011).

Estas dinámicas que concentran riqueza y generan pobreza reproducen lógicas excluyentes también en el espacio público:

para los residentes de estas periferias pobres, la limitación en el acceso a la metrópolis implica no sólo el desarrollo de actividades laborales en el medio local - usualmente precarias - sino también la inaccesibilidad a todo lo que ofrecen otras zonas de la ciudad; y en última instancia, la falta de acceso a la ciudad misma (Lindón, 2006:21).

Ello también se ve reflejado en el modo en el que se habitan los espacios públicos de la ciudad donde muchas veces la alteridad se representa como un potencial peligro, donde los estigmas y el rechazo se agigantan y donde el miedo gana terreno sobre la ciudadanía y el derecho a la ciudad. ¿Se propone la Calle Recreativa romper con estas dinámicas?

Como no hemos encontrado antecedentes de trabajos sobre dicha política, trabajamos revisando el archivo de fuentes periodísticas locales (La Capital, Rosario 3 y Rosario Plus), documentos y sitios oficiales de la Municipalidad de Rosario (MR); a partir de la información brindada en una entrevista en profundidad realizada con su director Bruno Colautti, a fines de 2015 y a partir de la observación participante en el circuito. 
Abordaremos algunos de nuestros interrogantes organizando este artículo en tres partes. Una primera dedicada a ampliar las discusiones sobre el espacio público local tanto desde el miedo y los estigmas sociales como desde las fragmentaciones producidas por el auge del capital inmobiliario. Luego, avanzaremos en la descripción del proceso de implementación de la Calle Recreativa como escenario de las discusiones anteriores para, por último, indagar sobre los alcances y desafíos de dicha política en la ciudad de Rosario.

\section{LA ENAJENACIÓN DEL ESPACIO PÚBLICO COMO LUGAR DE ACCESO Y PERTENENCIA} A LA CIUDAD

La crisis del espacio público es resultado de las actuales pautas urbanizadoras, extensivas, difusas, excluyentes y privatizadoras. (Borja, 2013:112).

\section{Cuando el miedo ocupa el espacio público}

El espacio público ha sido concebido por numerosos autores como un lugar de sociabilización, de encuentro de lo diverso, de convivencia (Borja, 2013; Segovia y Dascal, Janoschka, 2004; 2000; Ziccardi, 2008 y 2011), de saber y poder (Foucault), de diálogo y política: de pluralidad (Arendt). Esto significa que el espacio público no se agota ni está asociado a lo físico espacial (...), es más bien un ámbito contenedor de la conflictividad social (...) (Carrión, 2016:17). Sin embargo, hoy en día algunos de esos mismos escritores entre otros, describen cómo dicho espacio público se ve imposibilitado de funcionar como nexo o lugar de pertenencia en la ciudad. Cómo ha sido enajenado por el miedo y la ambición financiera e inmobiliaria que lo han desplazado, privilegiando al espacio privado.

Ese corrimiento de la esfera pública a la privada (tampoco exenta de violencia y temores) es un movimiento complejo que desplaza el hacer en la ciudad, que construye muros, que excluye y es una de la multiplicidad de causas que acrecientan la violencia urbana y, cuanto menos, diluye vínculos o los crea a partir del temor y la desconfianza. En este punto es bueno advertir, siguiendo a Lindón (2008), que si bien miedo y violencia están relacionados, uno se trata de un sentimiento frente a potenciales conductas que nos amenazan; mientras que, la otra es una de esas acciones que al ejercerse pueden provocar el sentimiento anteriormente descripto.

Por lo que, el "miedo citadino" puede preceder o no a un acto de violencia y, si bien, es un sentimiento individual se trata de una construcción social que se traspasa de boca en boca y es producido ante el deterioro de ciertas identidades sociales. Como decía Goffman, la sociedad 
establece los medios para clasificar a las personas y determinar en qué categoría se hallan, es decir determinar su identidad social. De este modo, se le asignan atributos descalificadores a ciertos sujetos que en este caso, serían potencialmente peligrosos y por tanto, generadores de temor y "merecedores" del rechazo social.

Dicha estigmatización es percibida por el desacreditado tal vez en mayor medida que por quien la profesa que al encontrarse subsumido en un clima social de temor lo reproduce sin cuestionamientos, generalmente de manera injustificada. Esa percepción sumada a la inequidad que lo atraviesa en la distribución de bienes materiales y simbólicos -es decir en el acceso al derecho a la ciudad-, acrecienta las fragmentaciones socio-territoriales que se vuelven del todo evidentes en la cartografía vívida de la ciudad.

La complejidad de esa realidad urbana nos lleva a apartar aquellas viejas concepciones que simplifican la noción de periferia a la idea de un círculo en el margen urbano donde habitan los sectores pobres, dado que eso implica reducir la conflictividad que representa, eliminar sus "rugosidades" (Santos, 2006), mostrándola como un espacio liso, lejano... cuando la desigualdad es, en verdad, un fenómeno socio-territorial. Es decir, un fenómeno socialmente producido que tiene manifestaciones y articulaciones espaciales claras y que, a su vez, se nutre de ellas (Di Virgilio y Perelman, 2014:9).

Así actualmente, en primer lugar, no todas las periferias son pobres; algunas, muy por el contrario, se construyen entre muros en el acrecentado proceso de gentrificación que analizaremos en el próximo apartado. Segundo, habitar un barrio popular periférico no sólo implica complicaciones para acceder a los servicios básicos, horas para trasladarse hacia el centro, relegación en los niveles de conectividad, sino también un "sentir/se" desplazados que perciben los sujetos que ocupan estos lugares (Soldano, 2008; Ziccardi, 2011) ante la supuesta ausencia de los atributos necesarios para "pertenecer" a la ciudad.

Carrión (2016:37) lo resumen diciendo: en la ciudad de la dispersión o expansiva se hace difícil construir el sentido de pertenencia y de reconocimiento en su unidad, porque la centralidad urbana, como espacio público se desvanece como factor integrador debido a la dispersión periférica y a que la centralidad adopta forma de flujo. Es decir, que el espacio público se convierte en un lugar de movimiento, en "un pasar" de manera fugaz ya sea por necesidad de circular o consumir, desechando en lo posible el transporte público como forma de locomoción y todo aquello que implique un mayor contacto con la alteridad. Inclusive, reclamando a las autoridades mayor control social y represión preventiva sobre ellos (Lindón, 2008; Borja, 2013).

Revista de Direito da Cidade, vol. 08, no 4. ISSN 2317-7721 pp.1403 - 14221408 
De este modo, el espacio público pierde gradualmente su función convivencial, integradora, expresiva de las aspiraciones de la ciudadanía y del ejercicio o reivindicación de sus derechos (Borja, 2013:242), aunque no por ello deja de ser un espacio de poder, de expresión ciudadana, sobre todo, ante ciertas manifestaciones colectivas generalmente asociadas a ese miedo -marchas por inseguridad, violencia de género, etc.- que paradójicamente a la vez que excluye, unifica voluntades. Tal vez porque dicho miedo contribuye a la formación de micro-territorios en donde se crea la ilusión de reducir la heterogeneidad para reducir la violencia/miedo, mientras que lo que se reduce es la vida urbana misma (Lindón, 2008:13).

\section{Cuando el negocio inmobiliario ocupa el espacio público}

Como señalamos en la introducción Rosario ha vivenciado un fuerte auge de la construcción en la década 2003-2013. Si bien la ciudad argentina posee características geográficas y sociales que colaboraron en dicho crecimiento e inclusive que no se sintiera el cimbronazo mundial de 2008, Rosario no es una excepción. En muchas partes del mundo existe:

“(...) el «nuevo urbanismo» que proclama las excelencias de la vida en comunidades apartadas (supuestamente íntimas y seguras, a menudo valladas y cerradas al exterior) en las que los promotores inmobiliarios prometen un estilo de vida refinado (...)" (Harvey, 2013:35).

Como bien nos sugiere el mismo autor en numerosas de sus obras (2008, 2013, etc.) el negocio inmobiliario es un excelente sector para colocar el excedente de capital de un pequeño grupo financiero especulativo. En este contexto, el aumento del valor de la tierra de manera exponencial ha, por un lado, imposibilitado el acceso a la vivienda para un sinnúmero de personas en América Latina, que se asientan sobre las tierras que casi no tienen ningún valor y que por tanto, se encuentran apartadas de la vida urbana, en general, sin tener cubiertos los requerimientos mínimos de infraestructura. Y, por el otro lado, numerosas áreas relegadas que se han reconfigurado como nuevas centralidades a partir de los llamados grandes proyectos urbanos (shoppings, supermercados de gran superficie, torres dedicadas a empresas generalmente del mercado global, etc.): que son nuevos espacios para nuevas formas de acumulación y de consumo (Cuenya, 2011:188).

A su vez, esta expansión de la ciudad se produce también por la reconfiguración de territorios periféricos también captados por el sector inmobiliario para la creación de barrios cerrados para población de clase media y alta que atemorizada decide restringir lo más posible su vida urbana. 
En estas centralidades se produce una fuerte tendencia a la gentrificación, a la ciudad-oferta hacia el exterior, a la ciudad-objeto, a la desposesión de los ciudadanos de su lugar (...) El espacio público ciudadano se pervierte en espacio-espectáculo o desaparece (de nuevo podríamos decir) engullido por las vías circulatorias (Borja, 2013:143).

He aquí la confluencia de los dos fenómenos que además de vincularse a través del miedo y la circulación por la ciudad, trae aparejada la disolución de los lazos urbanos, la fragmentación socio territorial y la utilización del espacio público sólo como vía de circulación.

¿Qué rol asume el Estado local en todo esto? Al decir de Harvey (2013:135):

desgraciadamente, la idea de los bienes comunes (como el derecho a la ciudad) está siendo tan fácilmente apropiada por el poder político existente como lo está siendo el valor a extraer de los bienes comunes urbanos por los intereses inmobiliarios.

Es decir, hay por parte de los gobiernos locales también una orientación hacia el sector privado y el turismo en las grandes ciudades (Cámara Menoyo, 2012). En general, fueron encandilados y seducidos por el capital financiero e inmobiliario que si bien trajo un gran crecimiento económico al interior, un aumento de la recaudación fiscal y una clara visibilidad internacional de las ciudades, profundizó las brechas sociales. Di Virgilio y Rodríguez (2015:238) lo llaman la tensión entre neoliberalismo y democracia en la ciudad, ante la cual el Estado interviene:

sólo en aquellos casos en que se han producido resistencias organizadas que han exigido respuestas de políticas y que, a su vez, han logrado instalar propuestas y debates más o menos públicos que las vinculan con la democracia en la ciudad, como un todo.

Esta nueva situación aumenta, la comenzada en la década de los 90, cooperación públicoprivado en la gestión de la ciudad. El mayor desafío en ello es lograr articular políticas públicas que no desplacen al ciudadano al lugar de consumidor y que superen aquel tipo de ciudad de sujetos aislados, que cuando se encuentran no saben convivir porque lo colectivo les es ajeno (Lindón, 2006:30)

Ello es posible a través de lo que Smolka y Amborski (2003:56) Ilaman recuperación de plusvalías: ya sea a través de su conversión en ingreso fiscal mediante impuestos o más directamente a través de mejoras locales para el beneficio de la comunidad. Es decir, se trata de un Estado local con rol de promotor de la redistribución equitativa del excedente en las ciudades. Una forma de ello es la creación y/o remodelación de los espacios públicos. Otra, el reacondicionamiento de la infraestructura básica (luminaria, cloacas, asfalto, etc.) en las zonas más olvidadas de la ciudad. Es generalmente allí donde, como señalan Di Virgilio y Rodríguez, (2015:344) aparecen resistencias, respuestas y propuestas alternativas ante la homogeneización de 
la lógica mercantil y los efectos gentrificadores. Borja (2013) lo llama el germen de la contrarrevolución mientras Cámara Menoyo (2012), nos habla de un urbanismo participativo.

Sin embargo, para recuperar dichas voces se requiere de un Estado local presente que promueva la construcción colectiva y participativa de la ciudad. El espacio público termina siendo el ámbito más significativo del conflicto urbano, sea como asedio por parte del capital o como expresión e integración de la sociedad (Carrión, 2016:15). Veamos qué sucede en Rosario a partir del estudio de la Calle Recreativa.

\section{CICLOVÍAS RECREATIVAS: "CAMBIANDO EL AIRE"}

Más ciudad es aquella que optimiza y multiplica las posibilidades de contacto de la población, es decir es aquella que tiene buenos espacios públicos

(Carrión, 2016:24).

La consecuencia de los procesos desarrollados en el apartado anterior es una ciudadanía opacada por la competencia (propia del consumo), la desconfianza asociada al miedo al otro y el resguardo en lo privado.

Sin embargo, el espacio público - que en nuestra concepción excede lo espacial y cuyo eje es lo relacional- es una construcción social que puede disminuir algunas barreras socio-territoriales según el modo en que se desarrolle la práctica espacial, es decir según el uso que reciben por parte de sus habitantes que puede ser diferente al espacio concebido por las gestiones locales (Lefrevre, 1974 en Delgado, 2013). Avancemos bajo este esquema sobre la Calle Recreativa.

\section{EL ESPACIO CONCEBIDO POR CICLOVÍAS PARA LAS AMÉRICAS}

Según la OPS (2009), las Ciclovías Recreativas son programas que consisten en abrir temporalmente las calles a los ciudadanos de manera segura y gratuita para la recreación, cerrándolas a la circulación vehicular. Se realizan en general un día fijo a la semana por períodos de tiempo breves, siendo la media de unas seis horas. La ciudad de Bogotá (Colombia) se conoce como la primera en darle inicio en 1974, aunque su crecimiento se ha dado de manera exponencial en el siglo XXI (ver imagen 1).

Actualmente el programa ocurre por lo menos 2 veces al mes en 12 países del continente americano.

Aproximadamente 33 ciudades cuentan con estos programas, además de otros 5 programas en municipios rurales. La longitud promedio de las calles utilizadas en los diferentes programas es $15.3 \mathrm{~km}$ (con un amplio rango de 1 
km a $121 \mathrm{~km}$ ) y la participación ciudadana por evento varía entre 60 y 1.000.000 personas (OPS, 2009:8).

A su vez, la Red de Ciclovías Recreativas (Red CRA) se constituye en el año 2005 en la ciudad colombiana con iniciativa de la OPS. Su conformación incentivó la replicación de experiencias:

El año 2009 fue marcado por el crecimiento rápido y exponencial de las Ciclovías Recreativas en el continente americano. Con menos de 40 ciudades desarrollándolas en el 2008, el número de iniciativas incrementó de más de un $150 \%$ entre 2009 y $2011 \ldots$

(http://cicloviasrecreativas.esy.es/red/).

Si bien se inician con el objetivo de incentivar la actividad física y la prevención en salud, las ciclovías alcanzan otro conjunto de prioridades urbanas como la concientización sobre la contaminación ambiental y los niveles de ruido y la recuperación-democratización del espacio público:

al apropiarse de los espacios urbanos, los ciudadanos aprenden valores de convivencia, comunicación, cohesión social, respeto, pertenencia, democracia e inclusión social. La Ciclovía Recreativa ofrece la oportunidad de tener una visión y experiencia diferentes de la ciudad, de recorrer espacios de importancia cultural y arquitectónica, y de transitar con seguridad en espacios tradicionalmente exclusivos de los vehículos (OPS; 2009:5).

\section{Imagen 1: Ciclovías en América}

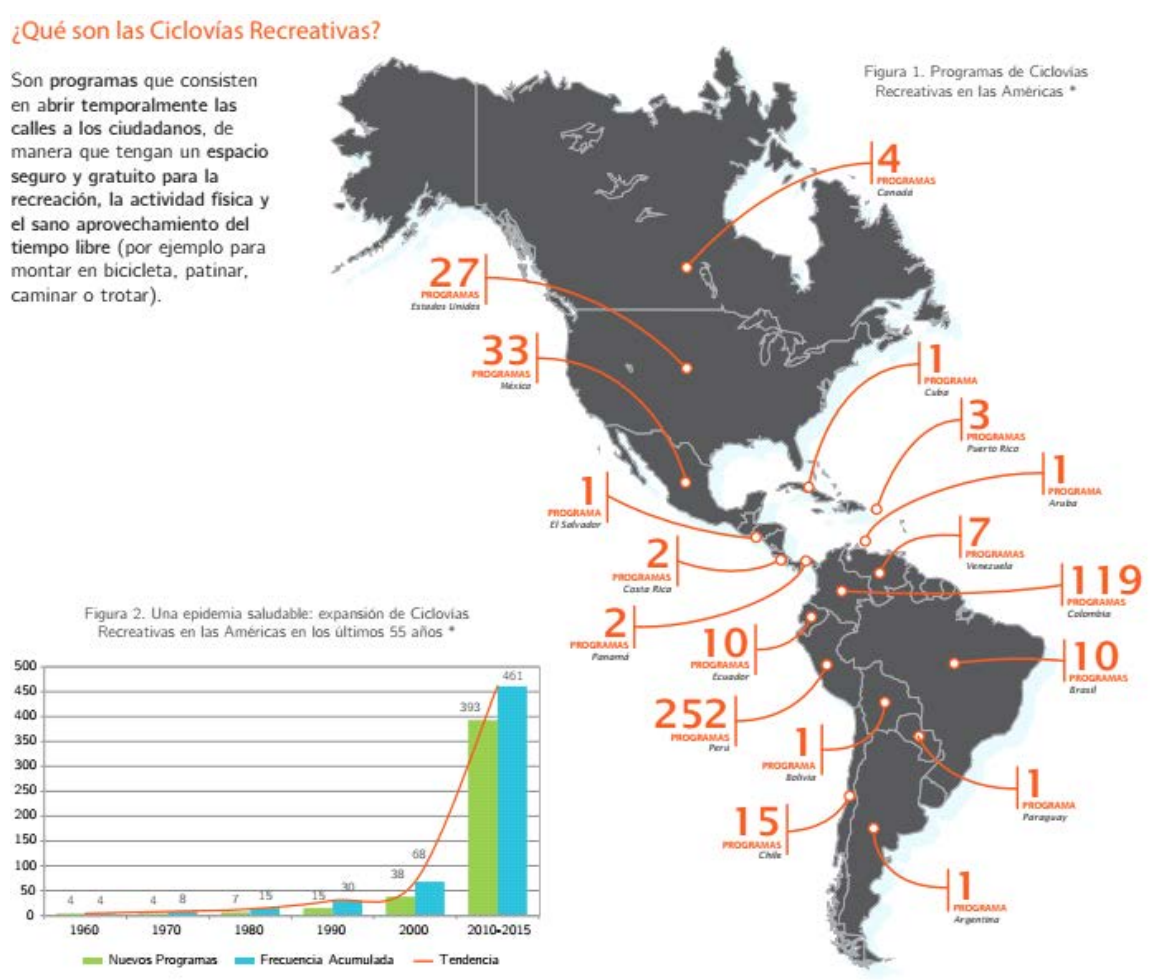

Fuente: https://epiandes.uniandes.edu.co/wp-content/uploads/Folleto_Ciclovias2015_DigitalFinal.pdf 
En este marco, la Red CRA ha elaborado un Código de Ética que establece los principios rectores de las experiencias de ciclovías recreativas que, entre otras cuestiones, regula el vínculo con los patrocinadores estipulando que por motivos de conflictos de intereses los apoyos financieros o en especies no puede provenir de: empresas tabacaleras o vinculadas al alcohol y otras drogas; compañías que pertenezcan a la industria de los refrescos, comida rápida y/o chatarra; y compañías productoras de automóviles.

\section{EL ESPACIO CONCEBIDO EN LA CIUDAD DE ROSARIO: CALLE RECREATIVA (2010-} 2015)

Desde el domingo 24 de octubre de 2010 se implementa en Rosario la llamada Calle Recreativa, única en su estilo en Argentina. Como iniciativa del Programa Rosario se Mueve, bajo la órbita de la Subsecretaría de Recreación y Deportes, dependiente de la Secretaría de Promoción Social de la Municipalidad de Rosario (una de las más golpeadas en materia de recursos humanos y monetarios en la última década, ver imagen 2).

Su puesta en marcha incluyó una amplia campaña de difusión, con encuestas a vecinos, entrevistas a comerciantes (bares, estaciones de servicio, supermercados, entre otros locales incluidos en el trayecto). Además de cartas informativas a sanatorios, taxistas, colectiveros, ambulancias y consorcios también involucrados cada domingo. Y por supuesto una amplia difusión a través de la página web municipal. En sus primeras semanas de funcionamiento no estuvo exenta de tensiones y disidencias pero con el correr de las ediciones la ciudadanía se fue apropiando del circuito y los comerciantes empezaron a acompañar también la iniciativa: Alejandro Aribe que es dueño del bar "Sr. Oroño", ubicado en uno de los primeros tramos en sumarse al recorrido del proyecto, afirma que la repercusión en la zona, y sobre todo en esa traza, "es muy buena: el negocio trabaja mucho con la gente, en especial con las familias que salen a pasear".

Imagen 2: Presupuesto Secretaría Promoción social (2006-2014)

\begin{tabular}{|c|c|c|c|c|c|c|c|c|c|}
\hline Año & $\mathbf{2 0 0 6}$ & $\mathbf{2 0 0 7}$ & $\mathbf{2 0 0 8}$ & $\mathbf{2 0 0 9}$ & $\mathbf{2 0 1 0}$ & $\mathbf{2 0 1 1}$ & $\mathbf{2 0 1 2}$ & $\mathbf{2 0 1 3}$ & $\mathbf{2 0 1 4}$ \\
\hline $\begin{array}{c}\text { Sec. } \\
\begin{array}{c}\text { Promoción } \\
\text { Social }\end{array}\end{array}$ & 55.683 .116 & 78.401 .058 & 75.076 .653 & 83.460 .161 & 99.453 .895 & 143.656 .694 & 178.126 .205 & 233.953 .916 & 323.694 .898 \\
\hline Total & 739.403 .004 & 914.539 .111 & 1.121 .380 .601 & 1.363 .918 .464 & 1.694 .662 .505 & 2.374 .489 .906 & 2.900 .371 .301 & 4.036 .258 .207 & 5.459 .614 .679 \\
\hline $\begin{array}{c}\text { \% sobre } \\
\text { el total }\end{array}$ & $\mathbf{7 , 5 3 1}$ & $\mathbf{8 , 5 7 3}$ & $\mathbf{6 , 6 9 5}$ & $\mathbf{6 , 1 1 9}$ & $\mathbf{5 , 8 6 9}$ & $\mathbf{6 , 0 5 0}$ & $\mathbf{6 , 1 4 1}$ & $\mathbf{5 , 7 9 6}$ & $\mathbf{5 , 9 2 9}$ \\
\hline
\end{tabular}

Fuente: elaboración propia en base a datos oficiales MR. Cifras expresadas en pesos argentinos. 
El encuentro se realiza cada domingo de 8:30 a 12:30 hs (reduciéndose la jornada que en sus inicios era de 8 a 13 hs en marzo de 2013) período en el cual se prohíbe el tránsito vehicular. Si bien la restricción del tráfico es total para las calles señaladas, quienes viven sobre esas arterias pueden usar los automóviles -a paso de hombre- en caso de necesidad y tomar la primera de las calles transversales ya que estos cruces no se cortan. Lo mismo rige para las estaciones de servicio, clínicas y comercios con estacionamiento propio.

De acuerdo a cifras oficiales circulan en promedio unas 30 mil personas por domingo (que surgen de contar cuántas personas pasan cada hora por puntos fijos del circuito) acumulándose entre 2010 y 2015, 7,5 millones de visitas que pudieron disfrutar del circuito municipal que une a tres distritos, Centro, Sur y Norte, según narra el Diario La Capital en una nota realizada para su tercer aniversario. Actualmente la Calle Recreativa se extiende a lo largo de $28 \mathrm{~km}$ que unen puntos de esos tres distritos de la ciudad, no casualmente los de mejores indicadores socioeconómicos como puede verse en la siguiente tabla.

Tabla Nro 1: Características Distritos Ciudad de Rosario

\begin{tabular}{|c|c|c|c|c|c|c|}
\hline $\begin{array}{l}\text { Distrito/ } \\
\text { Variable }\end{array}$ & Centro & Norte & Noroeste & Oeste & Sudoeste & Sur \\
\hline $\begin{array}{c}\text { Población } \\
2001\end{array}$ & 261.047 & $\begin{array}{l}131.495 \\
127.882\end{array}$ & 144.461 & 106.356 & 103.446 & 160.771 \\
\hline 2010 & 243.650 & 137.883 & 170.765 & 135.481 & 114.276 & 146.257 \\
\hline Superficie & $\begin{array}{c}20,66 \mathrm{~km} 2 \\
11,5 \%\end{array}$ & $\begin{array}{c}34,88 \mathrm{~km} 2 \\
19,5 \%\end{array}$ & $\begin{array}{c}43,82 \mathrm{~km} 2 \\
24,5\end{array}$ & $\begin{array}{c}40,42 \mathrm{~km} 2 \\
22,6 \%\end{array}$ & $\begin{array}{c}20,13 \mathrm{~km} 2 \\
11,2 \%\end{array}$ & $\begin{array}{c}18,78 \mathrm{~km} 2 \\
10,51 \%\end{array}$ \\
\hline $\begin{array}{l}\text { Superficie } \\
\text { Urbanizada }\end{array}$ & $100 \%$ & $75 \%$ & $58 \%$ & $32 \%$ & $70 \%$ & $96 \%$ \\
\hline $\begin{array}{l}\text { Densidad } \\
\text { poblacional } \\
(2010)\end{array}$ & $\begin{array}{l}11.793,33 \\
\text { hab/km2 }\end{array}$ & $\begin{array}{l}3.953,08 \\
\text { hab/km2 }\end{array}$ & $\begin{array}{l}\text { 3.896,96 } \\
\text { hab/km2 }\end{array}$ & $\begin{array}{l}3.351,83 \\
\text { hab/km2 }\end{array}$ & $\begin{array}{l}5.676,90 \\
\mathrm{hab} / \mathrm{km} 2\end{array}$ & $\begin{array}{l}7.787,91 \\
\text { hab/km2 }\end{array}$ \\
\hline $\begin{array}{c}\text { Asentamientos } \\
\text { irregulares }\end{array}$ & $\begin{array}{c}\text { Más de } \\
2000 \text { hab. }\end{array}$ & $\begin{array}{l}\text { Más de } 10 \\
\text { mil hab. }\end{array}$ & $\begin{array}{l}\text { Más de } 30 \\
\text { mil hab. }\end{array}$ & $\begin{array}{c}\text { Más de } 35 \\
\text { mil hab. }\end{array}$ & $\begin{array}{c}\text { Más de } 30 \\
\text { mil hab. }\end{array}$ & $\begin{array}{c}\text { Más de } 20 \\
\text { mil hab. } \\
11,66\end{array}$ \\
\hline NBI (2001) & 3,43 & 9,06 & 14,29 & 21,06 & 15,81 & \\
\hline
\end{tabular}

Fuente: elaboración propia en base a datos oficiales MR

Aún así, en sus inicios el circuito estaba constituido por 13 km sólo en el Distrito Centro y Norte uniendo tres parques: Independencia, Sunchales y Scalabrini Ortíz. Luego se realizó una primera extensión, el 29 de abril de 2012, que comprendió las calles 27 de Febrero desde Oroño hasta San Martín y la calle San Martín hasta Boulevard Seguí, completando así los 20 kilómetros recorrido, abarcando la zona Sur de la ciudad. La tercera ampliación del circuito hacia el 
Monumento Nacional a la Bandera, se llevó a cabo el 14 de octubre del mismo año, alcanzándose los 28 kilómetros actuales en su doble traza (ver imagen 3). Ese mismo día se registró uno de los récords de asistencia de público, con la presencia de más de 66 mil usuarios durante una jornada de 5 horas.

Dentro de la construcción de este espacio concebido la Municipalidad de Rosario inscribe entre sus beneficios: la recreación gratuita y el aprovechamiento del tiempo libre (deporte y recreación, arte y cultura, desarrollo social); la recuperación de las calles para el encuentro ciudadano; la promoción de la convivencia ciudadana con valores democráticos; la adquisición de hábitos de vida saludables; la prevención de las enfermedades crónicas; la disminución de la congestión vehicular y la promoción de medios alternativos de transporte; la disminución de la contaminación ambiental y los niveles de ruido.

\section{Imagen 3: Mapa actual del Circuito Calle Recreativa Rosario}

\section{MAPA DEL ClRCUTHO}

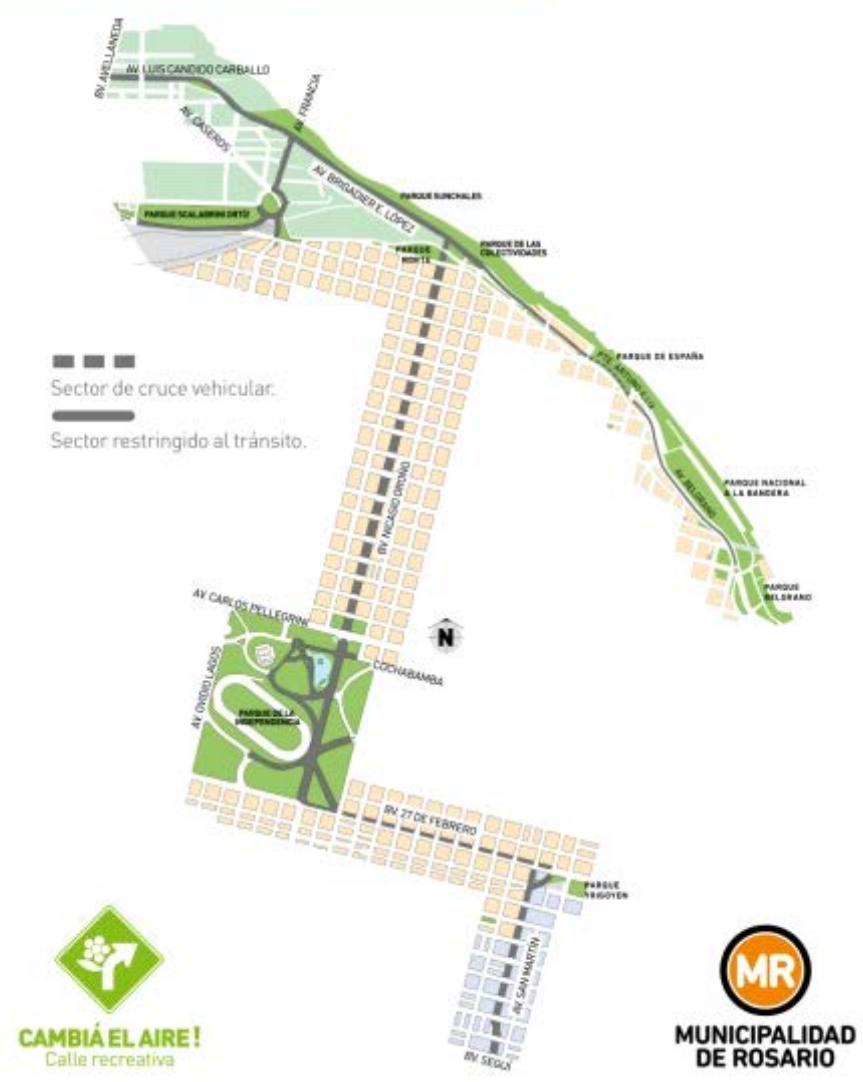

Fuente: MR 
A finales del año 2015, el oficialismo junto a un grupo de empresarios nucleados en el Centro Comercial a Cielo Abierto Pellegrini quisieron promover la extensión de la traza por Av. Pellegrini en la mano hacia el este. También se evaluó la aplicación del programa los días feriados. Hasta el momento, aunque el primer proyecto fue aprobado, ninguna de las dos iniciativas ha prosperado.

Al respecto, la actividad privada dentro del circuito está regida por el código de ética del la Red CRA y por la Ordenanza municipal Nro. 9051 de sponsoreo del deporte. El subsecretario de Recreación y Deportes local, Adrián Ghiglione, explica en una nota brindada al diario La Capital:

poco a poco se van reglamentando nuevos parámetros, dado que cada vez más empresas buscan asociar sus productos, su imagen de marca, con la vida saludable, y encuentran en este espacio una alternativa que a veces conspira con el espíritu con el que fue creado el circuito.

La coordinación público-privada es visible a lo largo del trayecto, sobre todo en las zonas del distrito Centro que lo componen. El director Bruno Colautti nos cuenta en la entrevista que más de 100 instituciones pasaron ya por el circuito y como poco a poco se fueron rompiendo las resistencias para incrementarse las demandas de que la Calle Recreativa pase por un determinado sector, como vimos el caso de los comerciantes de calle Pellegrini:

La iniciativa en principio provocó la negativa de muchos comerciantes y empresarios del rubro gastronómico, argumentando que el corte de calles impediría a clientes acercarse, y por ende, les quitaría rentabilidad. Pero hoy están conformes, e inclusive, algunos aumentaron sus ventas.

Lo mismo relata al periódico local la dueña de un bar en Oroño y Jujuy:

Los domingos a la mañana se llena de gente caminando o corriendo con sus perros o en grupos o en familia. De vuelta del río se sientan a desayunar o a tomar una gaseosa o un jugo y es por eso que tenemos abierto.

Carlos Glielmi es dueño de una reconocida marca de sándwiches en la zona Sur (San Martín al 3100):

Al principio, cuando nos avisaron de la implementación de la Calle Recreativa por San Martín, me cayó muy mal. Pensábamos que no iba a pasar nadie, pero cuando empezamos a darnos cuenta del movimiento que se genera, nos pareció bárbaro", repasa. Luego considera que, "a partir de que la gente pasa caminando por la zona, el cliente tiene más tiempo de ver qué negocios hay, lo que les permite ir descubriendo los comercios que tienen cerca de su casa.

Al parecer hay un estar ahí diferente del pasar habitual por la ciudad a lo largo del circuito. Según nos relata Colautti aproximadamente el 60 por ciento de la gente que recorre la Calle Recreativa, lo hace caminando o corriendo. En tanto, el 30 por ciento lo hace en bicicleta y un 10 por ciento en patines. Hay también, en relación a las actividades que se desarrollan semanalmente de manera sistemática (y con los cuales no se contaba al inicio), espacios que abren sus puertas a la 
comunidad como son: Ciudad de los Niños, Parque infantil de Educación Vial, Museo de la Ciudad, Feria de agricultura urbana, entre otros. Existen, además, diferentes puntos de encuentro donde de manera gratuita se dictan clases abiertas de gimnasia, maratones y caminatas solidarias organizadas por diferentes tipos de instituciones, empresas, ONGs, bicicleteadas temáticas, etc.

Imagen 4: Distribución de las postas y puntos de encuentro a lo largo del circuito

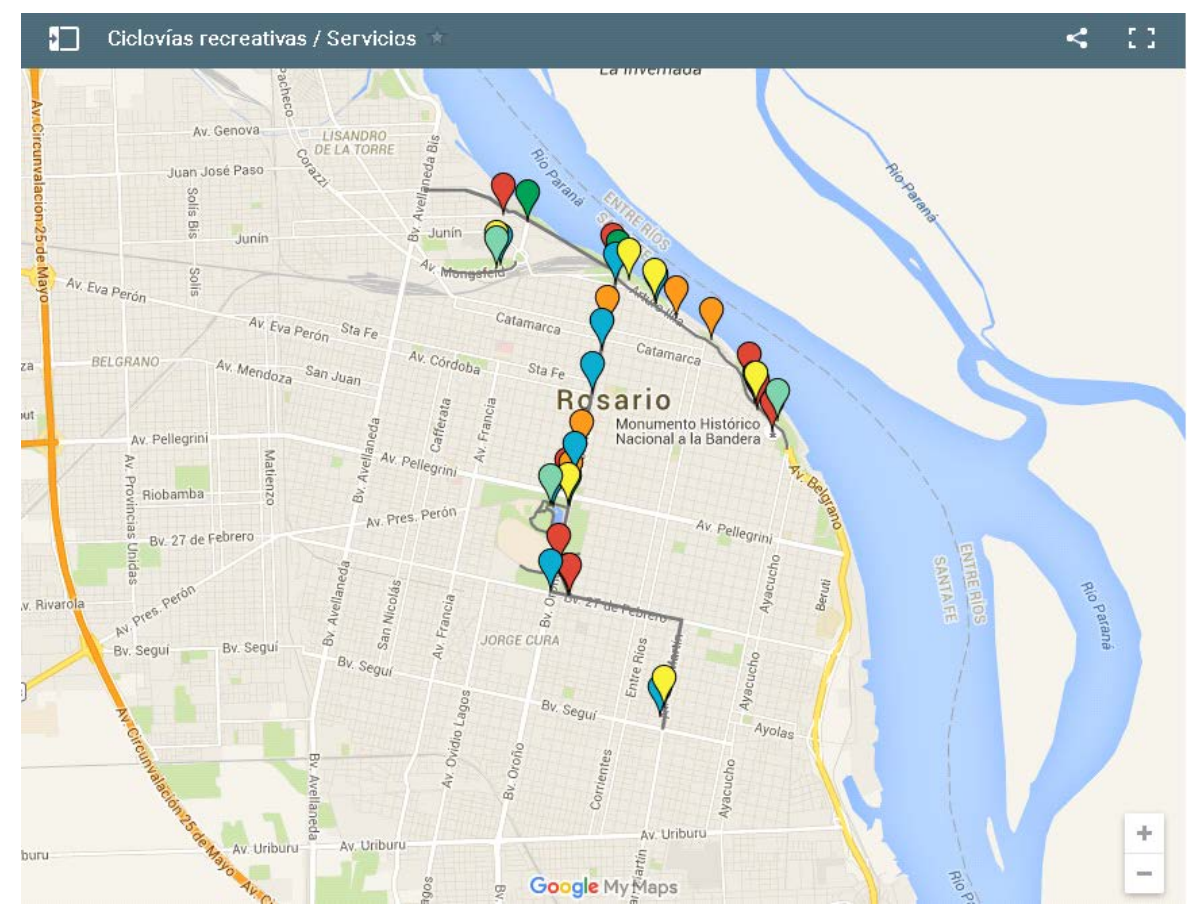

Fuente: MR

Cuando analizamos dicha distribución por sector nos encontramos con algo que es evidente en una recorrida por la Calle Recreativa, su esparcimiento en la cuadrícula urbana no es equitativo. Para que se pueda ver con claridad hemos ampliado y recortado el mapa del circuito en cuatro partes: zona Sur por Calle San Martín, 27 de Febrero hasta Calle Oroño y Av. Mendoza (imagen A y B); Oroño hacia el Río por la vía este hacia el Monumento a la Bandera (imagen C) y en su lado oeste hasta la zona Norte (imagen D). Los puntos rojos son museos y otras actividades recreativas municipales; los verdes señalizan parques; los amarillos son estaciones saludables ya sea donde se dan clases de gimnasia, yoga, etc. o se brinda bebidas a los transeúntes; los celestes es zona de servicios por ejemplo para las bicicletas. 


\section{Imagen 5: Distribución de las postas y puntos de encuentro por zona del circuito}

A.

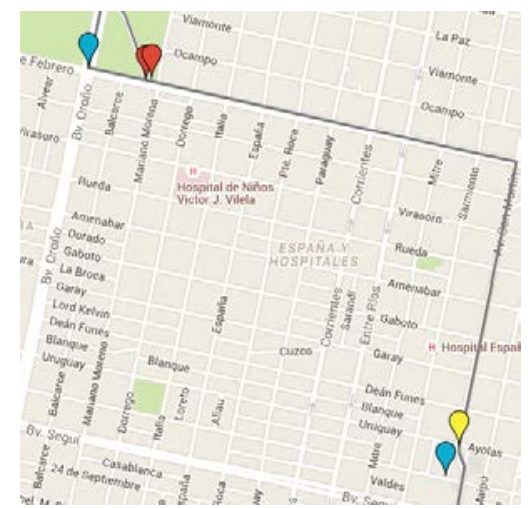

B.

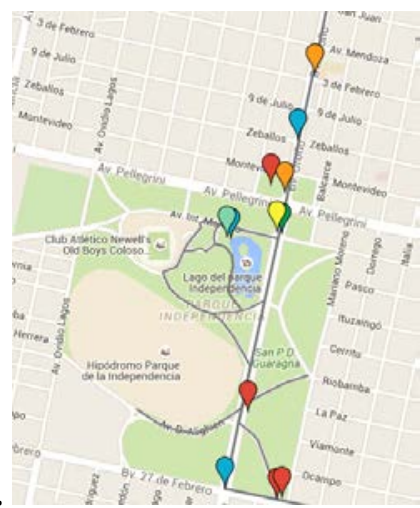

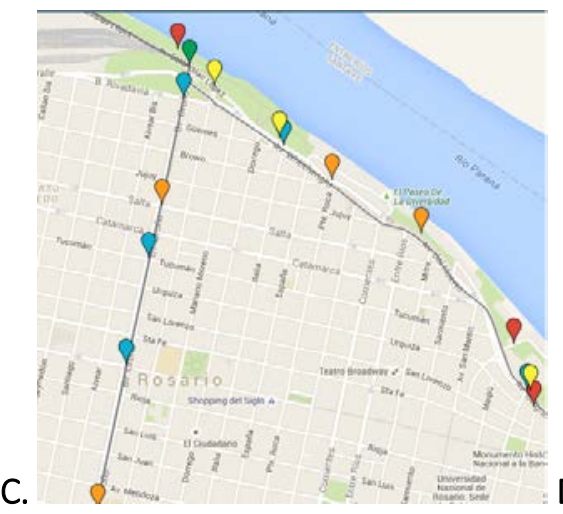

D.

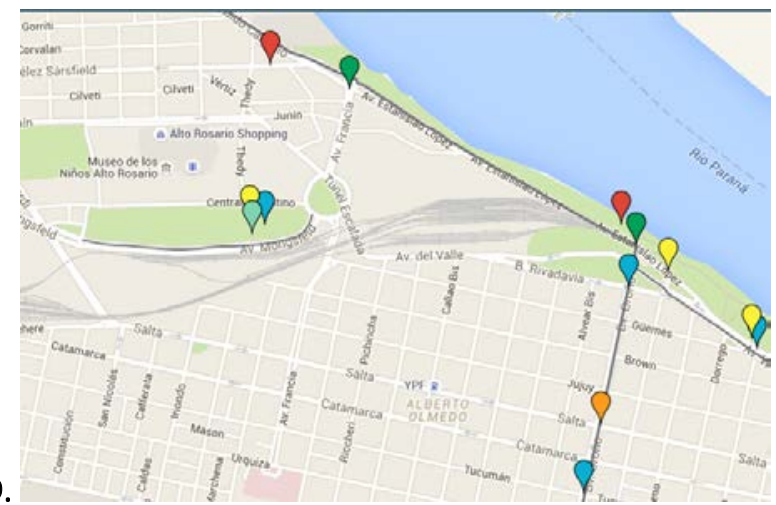

Algo parecido sucede con los puestos privados en el circuito que se asientan a través de una estrategia de marketing que el Municipio no controla. Por tanto, suelen concentrarse del mismo modo sobre calle Oroño y en la costa del río Paraná.

\section{EL ESPACIO VIVIDO SOBRE CALLE RECREATIVA EN ROSARIO. DESAFÍOS Y LIMITACIONES ACTUALES A MODO DE CONCLUSIÓN}

La Calle Recreativa es, a nuestro juicio, una novedosa alternativa de uso y construcción del espacio público en la ciudad de Rosario que detrás de las motivaciones personales que inducen a los vecinos a utilizarla de tipo recreativas y deportivas, colabora en un aprovechamiento de la ciudad diferente del habitual pasar.

Su puesta en marcha requiere un esfuerzo logístico municipal y de las fuerzas de seguridad vial en un día y horario poco frecuente que se resuelve con éxito semanalmente. Las resistencias de origen fueron apagándose debido a la alta apropiación que la ciudadanía hizo de las calles del circuito. 
La posibilidad de sponsoreo es también, hábilmente manejada por el Municipio local multiplicándose la cantidad de iniciativas a lo largo del recorrido. Aunque como mostramos en los mapas y se observa en una recorrida frecuente del mismo, hay una clara tendencia a asentarse en las zonas más pudientes de la ciudad localizadas sobre Bv. Oroño y el trazado lindante con el río. Claramente, el privado utiliza el espacio con fines comerciales y de publicidad y, por tanto, despliega sus estrategias comunicacionales para realizarlo en el o los lugares donde cree más ventajoso y rentable su participación en el circuito.

Estas actividades privadas de diferente índole sustentan a la propia Calle Recreativa ya que el canje es por materiales o recursos para el sostenimiento de la misma, que recibe escaso presupuesto municipal dentro de una Secretaría que hemos mostrado el recorte que ha sufrido en los últimos años. De este modo, el Estado no se inmiscuye en el modo en que estas actividades se despliegan en el territorio ni sustituye las mismas con aportes propios. Con lo cual, por ejemplo, dichas zonas del circuito poseen puestos de agua potable y otras bebidas azucaradas mientras en el resto escasean.

Este detalle que puede parecer menor es una replicación de las diferencias habituales que los vecinos sienten las gestión local realiza entre "el centro" y "los barrios" reproduciendo viejas fracturas urbanas. Lo cual es revalidado cuando analizamos el mismísimo trazado del circuito que se inicia principalmente en el Distrito Centro y algo del Norte seguido luego por un breve fragmento del Sur. ¿Acaso el resto de las zonas de la ciudad no merecen un aprovechamiento del espacio público semejante? Dal Lago, subsecretario de recreación y deportes afirma:

El sueño mayor es poder unir todos los distritos de la ciudad y que el domingo por la mañana se transforme en el día esperado por todos para encontrarse más que nunca con una ciudad saludable.

Sin embargo, no hay avances ni perspectivas en ese sentido. No obstante, dicha falencia no invalida lo que, desde nuestra perspectiva, es uno de los mayores aportes de la Calle Recreativa en Rosario: la disminución del miedo a transitar y convivir en el espacio público con los otros.

La vida urbana se desarrolla allí de una manera que demuestra que es posible construir ciudad en la diferencia y tolerancia hacia lo diverso sin temor a la alteridad. ¿A qué se debe esto? No se visualiza presencia policial en el circuito aunque sí hay agentes de tránsito y de la guardia urbana municipal. Lo cual desmitifica la idea de que el sentimiento de inseguridad sólo se reduce ante la presencia de fuerzas armadas en el territorio. El Estado local sólo tiene presencia demarcando los límites del circuito: "un adentro y un afuera" y sus márgenes temporales de inicio y fin cada domingo. Parecería haber similares códigos morales de convivencia en dicho espacio 
sumado a reglas institucionales claras que promueven la confianza, disminuyendo en apariencia lo que Míguez e Isla denominan fragmentación social subjetiva.

Dicha hipótesis sobre la sensación de seguridad del circuito es un supuesto en el que deseamos avanzar en futuras investigaciones siendo que numerosos autores acuerdan que allí donde la sociabilidad barrial es mayor, existen menores niveles de victimización (ver Míguez e Isla, 2010). Ahora, si bien parecería haber un "convivir en el espacio público diferente del pasar habitual", la Calle Recreativa muestra algunas dificultades de integración con los otros. Y, por tanto, se configura como un lugar de recreación individual y/o entre ya conocidos.

¿No podría ser acaso uno de esos micro-territorios de los que nos habla Lindón? ¿Es la Calle Recreativa en Rosario una ilusión de un territorio sin rugosidades y de allí la aparente reducción del miedo?

Más allá de los interrogantes que se abren, que son muchos, las potencialidades de la Calle Recreativa son numerosas y creemos que como experiencia innovadora en Argentina merece seguir profundizando su construcción como espacio colectivo.

\section{BIBLIOGRAFÍA}

AUGÉ, Marc (2000), Los no lugares. Espacios del anonimato. Editorial Gedisa. Quinta impresión. España.

BAREMBOIM, Cintia (2011), Estructuración, crecimiento y transformación urbana en la ciudad de Rosario. Proyección 10 Panificación territorial: presencias y ausencias. Vol 5 - I. Pp. 124 a 142.

BORJA, Jordi (2013), Revolución urbana y derechos ciudadanos. Editorial Café de las ciudades. Colección Urbanidad. Buenos Aires.

CAMARA MENOYO, Carlos (2012), Las iniciativas de participación ciudadana en el urbanismo. El urbanismo participativo, una nueva forma de entender la ciudad y la ciudadanía en la configuración de espacios públicos. URBS. Revista de Estudios Urbanos y Ciencias Sociales. Volumen 2, número 1, páginas 19-32 - $\quad$ Papers. España. Disponible en: http://www2.ual.es/urbs/index.php/urbs/article/viewFile/camara_menoyo/216

CARRIÓN, Fernando (2007), Espacio público: punto de partida para la alteridad. En: Espacios Públicos y Construcción Social. Hacia un ejercicio de ciudadanía de Olga Segovi. Ediciones Sur. Santiago de Chile.

(2014). La ciudad y su gobierno en América Latina. Documento de trabajo 20/2014. Instituto Iberoamericano. Universidad de Salamanca. España.

(2016), El espacio público es una relación, no un espacio. En Ramirez Kuri, Patricia, La reinvención del Espacio Público en la ciudad fragmentada. UNAM. México. 
CUENYA, Beatriz (2011), Grandes proyectos y sus impactos en la centralidad urbana. Cad. Metrop., São Paulo, v. 13, n. 25, pp. 185-212

DELGADO, Manuel (2013), El Espacio Público como Representación. Espacio urbano y espacio social en Henri Lefebvre. Oporto. Disponible en: http://www.oasrn.org/pdf_upload/el_espacio_publico.pdf

(s/f), El Espacio Público como ideología. S/d. Pp.57 a 65. Disponible en

http://www.fepsu.es/docs/urbandocs/URBANDOC1.pdf

DI VIRGILIO, Mercedes y PERELMAN, Mariani (coord.) (2014), Ciudades latinoamericanas. Desigualdad, segregación y tolerancia. CLACSO. Capital Federal. Argentina

DI VIRGILIO, Mercedes y RODRIGUEZ, Ma. Carla (2015), Ciudad de Buenos Aires: políticas urbanas neoliberales, transformaciones socio-territoriales y hábitat popular. Revista de Direito da Cidade Nro. 2, vol 6 ISSN 2317-7721. Pp. 323 a 347. Brasil.

FOUCAULT, Michel (1984), Des spaces autres. Dits et écrits. Disponible en castellano en: http://148.206.107.15/biblioteca_digital/articulos/7-132-1932qmd.pdf

HARVEY, David (2008), La libertad de la ciudad. Revista Antípoda no 7 Pp. 15-29. ISSN 1900-5407. Universidad de los Andes. Bogotá, Colombia.

(2013), Ciudades rebeldes. Del derecho a la ciudad a la revolución urbana. Editorial Akal S.A. Madrid, España.

JANOSCHKA, Michel (2004), El modelo de ciudad latinoamericana. Privatización y fragmentación del espacio urbano de Buenos Aires: el caso Nordelta. Pp. 87 a 117.

LINDON, Alicia (2006). La casa bunker y la deconstrucción de la ciudad. Revista LiminaR. Estudios sociales y humanísticos, año 4, vol. IV, núm. 2.Tuxtla Gutiérrez, Chiapas. México.

(2008), Violencia/miedo, espacialidades y ciudad. Revista Casa del tempo. Vol. I, época IV, Nro. 4. Pp. 8 a 14. Universidad Autónoma Metropolitana. México. Disponible en: http://www.uam.mx/difusion/casadeltiempo/04_iv_feb_2008/index.html

MIGUEZ, Daniel e ISLA, Alejandro (2010), Entre la inseguridad y el temor. Instantáneas de la sociedad actual. Paidos. Buenos Aires.

MONGIN, Olivier, (2006), La condición urbana. La ciudad a la hora de la mundialización. Editorial Paidós, Buenos Aires.

MUNICIPALIDAD DE ROSARIO (2004b), Experiencia Rosario, políticas para la gobernabilidad. PNUD. Rosario.

ORGANIZACIÓN PANAMERICANA DE LA SALUD (2009), Manual para implementar y promocionar la Ciclovía Recreativa. Colombia. Disponible en: http://cicloviarecreativa.uniandes.edu.co/

SANTOS, Milton (2006), A natureza do Espaço. Técnica e tempo. Razão e emoção. São Pablo Editora. Brasil 
SEGOVIA, Olga y DASCAL, Guillermo (2000), Espacio público, participación y ciudadanía. Ediciones Sur. Chile.

SEGURA, Ramiro (2009), Paisajes del miedo en la ciudad. Miedo y ciudadanía en el espacio urbano de la ciudad de La Plata. Cuaderno Urbano. Espacio, Cultura y Sociedad. Vol. 8 Nro.8. Pp. 51 a 91. Facultad de Arquitectura y Urbanismo de la Universidad Nacional del Nordeste. Chaco. Argentina.

SMOLKA, Martim y AMBORSKI, David (2003), Recuperación de plusvalías para el desarrollo urbano: una comparación inter-americana. Revista eure (Vol. XXIX, № 88), pp. 55-77, Santiago de Chile.

SOLDANO, Daniela (2008). Vivir en territorios desmembrados. Un estudio sobre la fragmentación socio-espacial y las políticas sociales en el Área Metropolitana de Buenos Aires (1990-2005). En: Ziccardi, Alicia (comp) Procesos de urbanización de la pobreza y nuevas formas de exclusión social. Los retos de las políticas sociales de las ciudades latinoamericanas del siglo XXI Siglo del Hombre Editores, CLACSO-Crop. Bogotá, Colombia.

WACQUANT, Loic (2013). Los condenados de la ciudad. Guetos, periferias y estado. 2da edición. Título original: Parias urbais. Ghetto, banlieues, État. Paris, 2006. Siglo XXI Editores, Buenos Aires

ZICCARDI, Alicia (2008). Pobreza y exclusión social en las ciudades del siglo XXI. En: Procesos de urbanización de la pobreza y nuevas formas de exclusión social Los retos de las políticas sociales de las ciudades latinoamericanas del siglo XXI. Siglo del Hombre Editores, CLACSO-Crop. Bogotá, Colombia.

(2011), Espacio público y participación ciudadana. El caso del Programa Comunitario de Mejoramiento Barrial de la Ciudad de México. Revista Gestión y Política Pública. Volumen Temático. PP. 187-226. México.

Trabalho enviado em 04 de setembro de 2016.

Aceito em 12 de outubro de 2016. 